\title{
The Impact of Family History on the Risk of Colorectal Neoplasia: Don't Change the Guidelines Just Yet!
}

\author{
N. Jewel Samadder • Lisa A. Cannon-Albright • \\ Randall W. Burt
}

Published online: 25 August 2012

(C) Springer Science+Business Media, LLC 2012

Colorectal cancer (CRC) is one of the most familial of all malignancies. Adenomatous polyps, the precursors of most CRCs, segregate with colon cancer in families and are found in excess in relatives of those with CRC [1]. The screening colonoscopy study by Tsai and Strum in this issue failed to find a statistically significant increased risk of advanced adenomas in persons with a first-degree relative with CRC compared to persons with no family history of CRC [2]. The results should be viewed with caution, however, in view of some of the subject exclusion criteria applied. Use of these criteria may also explain why the results of this study are at variance with similar studies that do demonstrate an excess of colonic neoplasia when a family history of CRC is present.

Luminal screening for CRC primarily detects adenomatous polyps and is believed to decrease CRC occurrence and mortality by removal of these precursor lesions. A few early malignancies are also found. In view of familial studies of CRC and adenomatous polyps, CRC screening guidelines now advise a younger age of screening onset as well as more frequent examinations depending

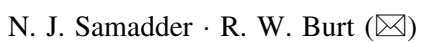

Division of Gastroenterology, Department of Medicine, University of Utah and Huntsman Cancer Institute, 2000 Circle of Hope, Salt Lake City, UT 84112, USA

e-mail: randall.burt@hci.utah.edu

L. A. Cannon-Albright

Division of Genetic Epidemiology, Department of Medicine, University of Utah and Huntsman Cancer Institute,

Salt Lake City, UT, USA

L. A. Cannon-Albright

George E. Wahlen Department of Veterans Affairs Medical

Center, Salt Lake City, UT, USA on the specifics of the family history of CRC and adenomatous polyps [3-5].

The study by Tsai and Strum is a prospective study of colonoscopy patients designed to assess whether CRC in a first-degree relative (FDR) increases the frequency of advanced neoplasia (adenoma $\geq 10 \mathrm{~mm}$, villous features, high-grade dysplasia, or adenocarcinoma) in the patient undergoing the procedure [2]. The authors prospectively evaluated 6,905 consecutive patients referred for screening colonoscopy to a single health system in Southern California between January 2005 and December 2006. A positive family history was defined as at least one firstdegree relative (parent, sibling or child) with colorectal cancer by patient report. The accuracy of this family history was not confirmed with records. The impact of family history was assessed by separating the study population into those with and without a family history of CRC and comparing the prevalence of advanced neoplasia found on examination. Colonoscopy patients were excluded if they had a personal history of colon neoplasia (colonic adenomas or CRC) or hemeoccult positive stools.

After applying exclusion criteria the investigators had 4,967 patients available for analysis. Of these, 643 (12.9\%) had a family history of at least one FDR with CRC while 4,324 did not. Among patients with a family history of CRC, $5.9 \%$ (38/643) had advanced neoplasia (CRC or advanced adenoma), compared to $4.9 \%$ (211/ 4,324 ) of patients without a family history. This was not statistically significant $(\mathrm{RR}=1.21,95 \%$ CI 0.87-1.69). Even when assessing the prevalence of advanced neoplasia in patients with an FDR diagnosed with CRC at less than 60 years old, no statistically significant increase in risk was found between those with and without a family history $(\mathrm{RR}=1.49 ; 95 \% \mathrm{CI}$ 0.91-2.48). It is important to note, however, that in the most advanced decade (80-89 year 
olds), at age where it might be argued to have the most accurate family history (which can only change in a positive direction as one ages), the RR of advanced neoplasia in those with a family history was estimated to be 10.22 (95\% CI 2.02-51.68).

The exclusion criteria of the study are somewhat problematic and included 837 patients excluded for "colonic neoplasia" or CRC, and 750 excluded for hematochezia, heme positive stools or anemia. Both groups would be much more likely to have advanced adenomas or CRC than the screening population studied. The resultant study population thus represents a population substantially depleted of individuals with CRC or adenomatous polyps (advanced or not). In the study group only 249 persons were found to have advanced adenoma. But 1,587 persons were excluded who were much more likely than the study group to have advanced neoplasia. This number could in fact completely overwhelm the number of those included in the study. Had those excluded been included, the results might have been very different.

The reason the exclusions are puzzling is that referral for family history of CRC or adenomas would be the issue that would bias a family history result. Those who were excluded in this study should not bias a family history result. Referral for colonoscopy based on a positive family history was not addressed in any of the groups, excluded or not.

It should also be noted that the findings of this study are at variance with CRC and adenomatous polyp studies reported in most prospective and retrospective observational studies to date. A study by Fuchs et al. [6] found that FDRs of CRC patients had a risk of CRC at age 40 that was similar to the risk of CRC in average risk patients at the age of 50 (RR 1.72; $95 \%$ CI 1.34-2.19).

Several observational studies explored the association between colonic adenomatous polyps and a family history of adenomas or CRC. Two French case-control studies examined this association in patients with a family history of CRC or large adenomas [7,8]. Their original casecontrol study in 1998 determined the risk of adenomas (small and large) in subjects with a family history of colorectal cancer [8]. They reported the risk of large adenomas was significantly increased by 2.5 in subjects with a family history of colorectal cancer. In an updated French study published in 2007, Cottet et al. then examined the association of colorectal cancer and large adenomas in first-degree relatives of patients with large adenomas. The investigators found an increased risk of 1.82 (95\% CI 0.71-4.69) for large adenomas, 3.90 (95\% CI 0.89-17.01) for colorectal cancer and 2.27 (95\% CI 1.01-5.09) for cancer or large adenomas [7].

A similar cross-sectional design study of asymptomatic Japanese adults undergoing CRC screening with colonoscopy asked subjects to complete a survey questionnaire asking about their FDR history of CRC or adenomas. This study reported a four-fold (OR 4.36; CI 1.60-10.21) elevated risk of $\mathrm{CRC}$ in FDRs of patients with adenomas [9]. This finding was supported by a US study which showed a significant increased risk of CRC in relatives of patients with advanced adenomas $(\geq 10 \mathrm{~mm}$ in size and/or with a villous component or high grade dysplasia) with an OR of 1.62 (95\% CI 1.16-2.26) [10]. A multicenter study by Lieberman et al. of subjects attending Veterans Administration medical facilities found an increased risk for advanced neoplasia in those with a family history of colorectal cancer (OR 1.5; $95 \%$ CI 1.1-2.0) [11]. A recent study at the University of Utah, using genealogy data for the entire state population and cancer data from the statewide Utah Cancer Registry showed significantly elevated risk of $\mathrm{CRC}$ in FDR, second degree relatives (SDR) and third degree relatives (TDR) of CRC cases [12]. Another study using the same resource estimated the risks of CRC in individuals with various combinations of affected FDR, SDR and TDR [13]. Statistically significant elevated risks were consistently found even when only TDR were affected with CRC. A lower age of diagnosis and the number of affected relatives of any degree further increased CRC risks, although the greatest risks were associated with affected FDRs.

Two meta-analysis/systematic reviews have also evaluated this question $[14,15]$. The systematic review by Johns and Houlston established that the risk of colorectal cancer increased by 2.25 (95\% CI 2.00-2.53) in FDRs of persons with CRC [15]. This finding was also confirmed in a more recent 2006 meta-analysis of 59 studies, which found a relative risk of 2.24 (95\% CI 2.06-2.43) associated with a history of colorectal cancer in FDRs. The strength of association varied according to number of affected FDR (from 1.85 for one relative to 3.97 for at least two affected relatives) and the age of relative at diagnosis (from 2.18 for relatives $>50$ years old and 3.55 for younger than 50 years old) [14].

As Tsai and Strum note, family history recall is reasonably good. It could be argued, however, that family history is one of the most significant data elements in this study, and that some sort of confirmation thus might have been attempted. Both prospective and retrospective studies to date (including this one) suffer from patient recall regarding family history of CRC or premalignant polyps that are not confirmed with records. A recent systematic review on the risk for CRC in persons with a family history of adenomas concluded that studies to date have several design problems that affect their validity and generalizability. The authors advocated for a well-designed crosssectional study that can identify all relatives and have access to medical records that would convincingly confirm a diagnosis of CRC, thereby reducing the effect of patient recall bias [16]. 
What can now be concluded regarding familial relationships between CRC and adenomatous polyps, advanced or not? And further, how should CRC screening guidelines reflect this familial risk? The weight of the evidence would certainly indicate that familial risk of CRC and adenomatous polyps is significant and should be included in CRC screening guidelines. Nonetheless it should also be acknowledged that this and other studies have limitations that may affect validity and generalizability. Future studies should incorporate the best methodologies and analytical tools available to further refine familial risk estimates and screening guidelines.

\section{Key Concepts}

- Colorectal cancer occurs with increased incidence in family members of personswith this malignancy, even outside the known inherited syndromes.

- Studies have shown that adenomatous polyps, the precursors of most colorectalcancers, also occur with increased incidence in relatives of persons withcolorectal cancer, and visa versa.

- Health policy organizations have included family history as a risk factor toconsider in colorectal cancer screening and have given specific screeningrecommendations related to the strength of the family history.

- The present study did not find an increased occurrence of advanced neoplasia(polyps $\geq 10 \mathrm{~mm}$, villous or advanced dysplasia component, or adenocarcinoma)in persons with a family history of CRC compared to those without.

- Ascertainment of subjects, however, excluded many patients with colonicneoplasia that may likely have affected the negative result.

- Future studies should incorporate the best methodologies and analytical toolsavailable to further refine familial risk estimates and screening guidelines beforeany changes are made in familial risk estimates of adenomatous polypoccurrence and CRC screening guidelines.

Conflict of interest Randall W. Burt is a consultant for Myriad Genetics. No other authors have a conflict of interest to disclose.

\section{References}

1. Jasperson KW, Tuohy TM, Neklason DW, Burt RW. Hereditary and familial colon cancer. Gastroenterology. 2010;138:2044-2058.
2. Tsai FC, Strum WB. Impact of a family history of colorectal cancer on the prevalence of advanced neoplasia at colonoscopy in 4,967 asymptomatic patients. Dig Dis Sci. 2011.

3. Levin B, Lieberman DA, McFarland B, et al. Screening and surveillance for the early detection of colorectal cancer and adenomatous polyps, 2008: a joint guideline from the american cancer society, the US multi-society task force on colorectal cancer, and the American College of Radiology. Gastroenterology. 2008;134:1570-1595.

4. Rex DK, Johnson DA, Anderson JC, Schoenfeld PS, Burke CA, Inadomi JM. American College of Gastroenterology guidelines for colorectal cancer screening 2008. Am J Gastroenterol. 2009; 104:739-750.

5. Burt RW, Barthel JS, Dunn KB, et al. NCCN clinical practice guidelines in oncology. Colorectal cancer screening. J Natl Compr Canc Netw. 2010;8:8-61.

6. Fuchs CS, Giovannucci EL, Colditz GA, Hunter DJ, Speizer FE, Willett WC. A prospective study of family history and the risk of colorectal cancer. N Engl J Med. 1994;331:1669-1674.

7. Cottet V, Pariente A, Nalet B, et al. Colonoscopic screening of firstdegree relatives of patients with large adenomas: increased risk of colorectal tumors. Gastroenterology. 2007;133:1086-1092.

8. Pariente A, Milan C, Lafon J, Faivre J. Colonoscopic screening in first-degree relatives of patients with 'sporadic' colorectal cancer: a case-control study. The Association Nationale des Gastroenterologues des Hopitaux and Registre Bourguignon des Cancers Digestifs (INSERM CRI 9505). Gastroenterology. 1998;115:7-12.

9. Nakama H, Zhang B, Fukazawa K, Abdul Fattah AS. Family history of colorectal adenomatous polyps as a risk factor for colorectal cancer. Eur J Cancer. 2000;36:2111-2114.

10. Lynch KL, Ahnen DJ, Byers T, Weiss DG, Lieberman DA. Firstdegree relatives of patients with advanced colorectal adenomas have an increased prevalence of colorectal cancer. Clin Gastroenterol Hepatol. 2003;1:96-102.

11. Lieberman DA, Weiss DG, Bond JH, Ahnen DJ, Garewal H, Chejfec G. Use of colonoscopy to screen asymptomatic adults for colorectal cancer. Veterans Affairs Cooperative Study Group 380. N Engl J Med. 2000;343:162-168.

12. Teerlink CC, Albright FS, Lins L, Cannon-Albright LA. A comprehensive survey of cancer risks in extended families. Genet Med. 2012;14:107-114.

13. Taylor DP, Burt RW, Williams MS, Haug PJ, Cannon-Albright LA. Population-based family history-specific risks for colorectal cancer: a constellation approach. Gastroenterology. 2010;138:877-885.

14. Butterworth AS, Higgins JP, Pharoah P. Relative and absolute risk of colorectal cancer for individuals with a family history: a meta-analysis. Eur J Cancer. 2006;42:216-227.

15. Johns LE, Houlston RS. A systematic review and meta-analysis of familial colorectal cancer risk. Am J Gastroenterol. 2001;96: 2992-3003.

16. Imperiale TF, Ransohoff DF. Risk for colorectal cancer in persons with a family history of adenomatous polyps: a systematic review. Ann Intern Med. 2012;156:703-709. 